\title{
TWENTY FIVE YEARS FIGHTING FOR WOMEN'S HEALTH AND RIGHTS: SOME PROGRESS BUT STILL A LONG WAY TO GO
}

\author{
Marleen Temmerman \\ Department of Public Health and Primary Care, Ghent University, Belgium \\ \& The Aga Khan University, Kenya \\ Former president of the Ghent Africa Platform (GAP)
}

\begin{abstract}
The aim of this paper is to provide an overview of 25 years women's health and rights, a difficult journey with steps forward and backwards since the landmark conference in 1994 when reproductive rights were for the first time on the menu. However, although great strides have been made in reducing maternal and child mortality since then, among others by the United Nations with the establishment of the Millennium Development Goals for 2015, showing that change is possible, many countries are still lagging behind in reaching the goals. While the new global architecture, in particular with the Sustainable Development Goals and the Global Strategy for Women's, Children's and Adolescents' Health, ensures that these issues remain high on the political agenda, this paper argues that we must move from political commitment to action, via the creation and dissemination of research evidence. As the Founding President of the Ghent Africa Platform (GAP) at Ghent University, I still believe GAP has an important role to play regarding this international collaboration and dissemination of scientific knowledge.
\end{abstract}

KEYWORDS: WOMEN'S HEALTH, WOMEN'S RIGHTS, REPRODUCTIVE RIGHTS, UN DEVELOPMENT GOALS

\section{Introduction}

The aim of this paper is to provide an overview of 25 years women's and health an rights, a difficult journey with steps forward and backwards since the landmark conference in I994 when reproductive rights were for the first time on the menu. The I994 International Conference on Population and Development (ICPD) in Cairo articulated a bold new vision about the relationships between population, development and individual wellbeing. At the 1994 ICPD Conference, I79 countries adopted a forward-looking, 20-year Programme of Action that continues to serve as a comprehensive guide to people-centred development progress. The ICPD Programme of Action was remarkable in its recognition that reproductive health and rights, as well as women's empowerment and gender equality, are cornerstones of population and development programmes (I).

At the Millennium Summit of the United Nations in 2000, the Millennium Development Goals (MDGs) were established following the adoption of the United Nations Millen- 
nium Declaration with eight international development goals for the year 2015 to be reached by the year 2015. Health was very central in the MDG agenda with 3 goals targeting health goals such as HIV, malaria, tuberculosis (MDG6), child health (MDG 4: to reduce the under 5 child mortality rate by two thirds between 1990 and 2015) and maternal health (MDG 5 ; to reduce the maternal mortality ratio by three quarters between 1990 and 2015 and achieve universal access to reproductive healthcare by 2015). It took another 7 years however, to adopt MDG 5 b which includes universal access to reproductive health care.In 20I0, confronted with unacceptably high rates of maternal and child mortality, the UN secretary general called on the world to develop a strategy to improve maternal and child health in the world's poorest and high burden countries, starting with 49 low income countries. The 2010 Global Strategy for Women's and Children's Health was a bellwether for a global movement and led to significant progress worldwide in women's and children's survival and health. The Every Woman Every Child movement that grew out of the Global Strategy mobilised stakeholders in all sectors to work towards shared goals. It fostered national leadership, attracted new resources and financial commitments, and created a worldwide movement of champions for the health and wellbeing of every woman and every child.

The year 2015 marked a defining moment for the health of women, children, and adolescents. It was not only the end point of the United Nations' millennium development goals (MDGs) and their transition to the sustainable development goals (SDGs), but also the 2oth anniversary of the International Conference on Population and Development's plan of action and the Beijing Declaration and platform of action.

This was a moment of reflection as well as celebration. Although great strides have been made in reducing maternal and child mortality during the MDGs, showing that change is possible, many countries were still lagging behind in reaching goal 4 and goal 5 , with vast inequities between and within countries

During the MDG era, good progress has been made towards realising the vision to end all preventable maternal, newborn, and child deaths within a generation. Millions of lives have been saved, and progress towards the health related millennium development goals was accelerated. Child mortality fell by $49 \%$ and maternal mortality by $45 \%$ between 1990 and 20I3. Strides forward were made in areas such as access to contraception and maternal and child health services, skilled attendance at births, reduced malnutrition, newborn interventions, management of childhood illnesses, immunisations, and combating HIV and AIDS, malaria, and tuberculosis (2).

Reproductive, maternal, newborn, and child health (RMNCH) has been a priority for both governments and civil society in low- and middle-income countries (LMICs). This priority was affirmed by world leaders in the Millennium Development Goals (MDGs) that called for countries to reduce child mortality by 67 percent and maternal mortality by 75 percent between 1990 and 20I5. Although substantial progress on these targets has been made, few countries achieved the needed reductions. The United Nations (UN) Secretary-General's Global Strategy for Women's and Children's Health, launched in 2010 and expanded in 2015 to include adolescents, is an indication of the continued global 
commitment to the survival and well-being of women and children (3).

Annual official development assistance for maternal, newborn, and child health has increased from US\$2.7 billion in 2003 to US\$8.3 billion in 2012, when there was an additional US $\$ 4.5$ billion for reproductive health (4). A continued focus on reproductive, maternal, newborn, child and adolescent health (RMNCAH) is needed to address the remaining considerable burden of disease in LMICs from unwanted pregnancies; high maternal, newborn, and child mortality and stillbirths; high rates of undernutrition; frequent communicable and noncommunicable diseases; and loss of human capacity (3). Cost-effective interventions are available and can be implemented at high coverage in LMICs to greatly reduce these problems at an affordable cost. RMNCAH encompasses health problems across the life course from adolescent girls and women before and during pregnancy and delivery, to new borns and children. An important conceptual framework is the continuum-of-care approach in two dimensions. One dimension recognizes the links from mother to child and the need for health services across the stages of the life course. The other is the delivery of integrated preventive and therapeutic health interventions through service platforms ranging from the community to the primary health center and the hospital (3).

\section{The sexual and reproductive health and rights agenda}

Sexual and reproductive health and rights (SRHR) are fundamental to people's health and survival, to economic development, and to the wellbeing of humanity. Several decades of research have shown - and continue to show - the profound and measurable benefits of investment in sexual and reproductive health. Through international agreements, governments have committed to such investment. Yet, progress has been stymied because of weak political commitment, inadequate resources, persistent discrimination against women and girls, and an unwillingness to address issues related to sexuality openly and comprehensively (5).

Health and development initiatives, including the 2030 Agenda for Sustainable Development and the movement toward universal health coverage, typically focus on particular components of SRHR: contraception, maternal and newborn health, and HIV/AIDS. Countries around the world have made remarkable gains in these areas over the past few decades, but the gains have been inequitable among and within countries, and services have often fallen short in coverage and quality. Moreover, in much of the world, people have insufficient access to a full set of sexual and reproductive health services, and their sexual and reproductive rights are not respected or protected. Acceleration of progress therefore requires adoption of a more holistic view of SRHR and tackling of neglected issues, such as adolescent sexuality, gender-based violence, abortion, and diversity in sexual orientations and gender identities.

Progress in SRHR requires confrontation of the barriers embedded in laws, policies, the economy, and in social norms and values - especially gender inequality - that prevent people from achieving sexual and reproductive health. Improvement of people's wellbeing depends on individuals' being able to make decisions about their own sexual and re- 
productive lives and respecting the decisions of others. In other words, achieving sexual and reproductive health rests on realising sexual and reproductive rights, many of which are often overlooked - eg, the right to control one's own body, define one's sexuality, choose one's partner, and receive confidential, respectful, and high-quality services.

To address these issues, The Lancet and Guttmacher Institute, decided to join forces and to set up a Commission to review evidence in the field of SRHR. The Guttmacher-Lancet Commission report presents evidence needed to review the scope of the unfinished SRHR agenda (5) Each year in developing regions, more than 30 million women do not give birth in a health facility, more than 45 million have inadequate or no antenatal care, and more than 200 million women want to avoid pregnancy but are not using modern contraception. Each year worldwide, 25 million unsafe abortions take place, more than 350 million men and women need treatment for one of the four curable sexually transmitted infections (STIs), and nearly 2 million people become newly infected with HIV. Additionally, at some point in their lives nearly one in three women experience intimate partner violence or non-partner sexual violence. Ultimately, almost all $4 \cdot 3$ billion people of reproductive age worldwide will have inadequate sexual and reproductive health services over the course of their lives (5).

Other sexual and reproductive health conditions remain less well known but are also potentially devastating for individuals and families. Between 49 million and I80 million couples worldwide might be affected by infertility, for which services are mainly available only to the wealthy. An estimated 266 ooo women die annually from cervical cancer even though it is almost entirely preventable. Men also suffer from conditions, such as STIs and prostate cancer, that go undetected and untreated because of social stigma and norms about masculinity that discourage them from seeking health care (5).

Key messages of the report include:

I. Sexual and reproductive health and rights (SRHR) are essential for sustainable development because of their links to gender equality and women's wellbeing, their impact on maternal, newborn, child, and adolescent health, and their roles in shaping future economic development and environmental sustainability.

2. Everyone has a right to make decisions that govern their bodies, free of stigma, discrimination, and coercion. These decisions include those related to sexuality, reproduction, and the use of sexual and reproductive health services.

3. SRHR information and services should be accessible and affordable to all individuals who need them regardless of their age, marital status, socioeconomic status, race or ethnicity, sexual orientation, or gender identity.

4. The necessary investments in SRHR per capita are modest and are affordable for most low-income and middle-income countries. Less-developed countries will face funding gaps, however, and will continue to need external assistance.

5. Countries should incorporate the essential services defined in this report into universal health coverage, paying special attention to the poorest and most vulnerable people. 
6. Countries must also take actions beyond the health sector to change social norms, laws, and policies to uphold human rights. The most crucial reforms are those that promote gender equality and give women greater control over their bodies and lives

\section{Role of research, evidence generation and knowledge sharing}

As elaborated above, despite substantial progress during the Millennium Development Goals era, figures remain staggering: 303000 women died due to pregnancy or childbirth-related causes in 2015 (6); 225 million women wanting to avoid pregnancy do not use safe and effective family planning ( 7 ); and $45 \%$ of all under- 5 deaths happen during the neonatal period (8).

Accelerated efforts are needed to complete the unfinished agenda in reproductive, maternal, newborn and adolescent health and rights. The consolidated evidence base of what works in tackling poor RMNCAH has not overcome the gap in implementation, for neither cure nor prevention. Policy decisions should be informed by evidence, and for this we need more investment in the collection, analysis, and dissemination of high-quality data, together with a greater investment in implementation research to understand health systems and test solutions in a range of situations and contexts (9).

Inequity is a key factor to consider in RMNCAH research, particularly regarding adolescents and migrants. Innovative approaches are needed to ensure quality of care for adolescents for whom few specialised services are available, and for the large numbers of migrants with a documented lack of access to health services.

The Global strategy for women's, children's and adolescents' health (2016-2030) provides a roadmap for ending preventable deaths of women, children and adolescents by 2030 and helping them achieve their potential for and rights to health and well-being in all settings. The global strategy has three objectives: survive (end preventable deaths); thrive (ensure health and well-being); and transform (expand enabling environments). These objectives are aligned with 17 targets within nine of the sustainable development goals (SDGs), including SDG 3 on health and other SDGs related to the political, social, economic and environmental determinants of health and sustainable development (Io).

The development of effective, innovative solutions requires collaboration between academic researchers from different disciplines, scientists, health care providers, and - perhaps most importantly - women, their families, and communities. The involvement of end users in identifying problems and solutions provides vital insights and increases the likelihood that solutions will be taken up at scale; their involvement should be part of the assessment criteria of any research proposal (9).

The new global architecture, with the Sustainable Development Goals and the Global Strategy for Women's, Children's and Adolescents' Health, ensures that RMNCAH remains high on the political agenda. However, we must move from political commitment to action, via the creation and dissemination of evidence (9).

The commitment of the research community should go beyond conducting and publishing research findings: from conception until the use of results, any research should be carried out in continuous partnership - with policy makers, politicians, development 
partners, and the media - to ensure that evidence is properly translated into policy and practice. We are far from reaching the goal of safe pregnancy and childbirth for all women and girls, and of reaching sexual and reproductive health and rights in all countries. Research and innovation are essential ingredients for progress (9).

Stakeholders and development partners are called to leveraging their investment in research and innovation with new funding modalities aiming at mobilising new and innovative actors.

Partnerships is one of the 17 SDGs, key to reach the goals by 2030; the research community is a crucial partner moving the agenda forward with knowledge gathering and evidence creation and innovation.

As the Founding President of the Africa Platform at Ghent University (GAP) when it was established in 2007, I am proud and humbled to recognize and appreciate the role of GAP in international university collaboration, not only in the field of health but also in a wide variety of other research domains. As a truly academic platform, the Africa Platform unites all expertise on Africa available at the university and its associated colleges of higher education, and over the last decade it has had a considerable impact on fostering academic collaboration between Ghent University Association and African universities. GAP has brought academics together, across various disciplines and countries, it has inspired academics to engage in joint research, and it has motivated students to travel to Africa for fieldwork or teaching. These types of north-south collaboration are enriching for the different partners: they lead to stronger networks, to state-of-the-art science, and to more friendship, respect and understanding between academics across the globe. Regional platforms or networks such as the Africa Platform always have a positive impact on knowledge generation and research, and on partnering with non-academic stakeholders (NGOs, media, policy makers) when it comes to implementing research findings. All of this remains essential to address many of the world's challenges, of which reproductive health is a leading example.

\section{References}

(I) Programme of Action of the International Conference on Population Development, 2oth Anniversary Edition, isbn 978-0-89714-022-5; Copyright $\odot$ 2014, United Nations Population Fund

(2) Temmerman M, Khosla R2, Bhutta ZA, Bustreo F.Towards a new Global Strategy for Women's, Children's and Adolescents' Health. BMJ. 2015 Sep I4; 35I

(3) Global Strategy for Women and Child Health. https://www.everywomaneverychild.org/images/ content/files/global_strategy/full/20roogr4_gswch_en.pdf

(4) Black RE, Walker N, Laxminarayan R, Temmerman M. Reproductive, Maternal, Newborn, and Child Health: Disease Control Priorities, Third Edition (Volume 2). Washington (DC): The International Bank for Reconstruction and Development / The World Bank; 2016 Apr. Chapter I.

(5) Starrs AM, Ezeh AC, Barker G, Basu A, Bertrand JT, Blum R, Coll-Seck AM, Grover A, Laski L, Roa M, Sathar ZA, Say L, Serour GI, Singh S, Stenberg K, Temmerman M, Biddlecom A, Popinchalk A, Summers C, Ashford LS. Lancet. 20I8 Jun 30; 39I(I0I40):2642-2692. Accelerate progress-sexual and reproductive health and rights for all: report of the Guttmacher-Lancet Commission. 
(6) WHO, UNICEF, UNFPA, World Bank Group, UN Population Division. Trends in maternal mortality: I990 to 2015: estimates by WHO, UNICEF, UNFPA, World Bank Group and the United Nations Population Division. WHO, Geneva; 2015

(7) UN Population Fund Family planning; overview. http://www.unfpa.org/family-planning

(8) WHO Neonatal mortality; situation and trends http://www.who.int/gho/child_health/mortality/ neonatal_text/en/

(9) Depoortere $\mathrm{E}^{\mathrm{I}}$, Matthews $\mathrm{Z}^{2}$, Nove $\mathrm{A}^{3}$, Hanrahan $\mathrm{F}^{4}$, Kerstiëns $\mathrm{B}^{4}$, Matthiessen L4 , Temmerman $\mathrm{M}^{5}$, Draghia-Akli $\mathrm{R}^{4}$; speakers at the European Commission conference "Together for the next generation: research and innovation for maternal and newborn health" of Dec 8, 2015 The need for innovation and implementation research for maternal and newborn health. Lancet. 2016 Oct I; 388(10052):1374

(Io) Kuruvilla S, Bustreo F, Kuo T, Mishra CK, Taylor K, Fogstad H, Gupta GR, Gilmore K, Temmerman M, Thomas J, Rasanathan K, Chaiban T, Mohan A, Gruending A, Schweitzer J, Dini HS, Borrazzo J, Fassil H, Gronseth L, Khosla R, Cheeseman R, Gorna R, McDougall L, Toure K, Rogers K, Dodson K, Sharma A, Seoane M, Costello A. The Global strategy for women's, children's and adolescents' health (2016-2030): a roadmap based on evidence and country experience. Bull World Health Organ. 2016 May I; 94(5):398-400. 